\title{
Eastern Melodies in the Text of Plato
}

\author{
Ruzmatova Gulnoz Mirakhrarovna
}

\begin{abstract}
The article attempts to cover Platonic philosophical views, the theory of knowledge, the teachings of the state and the society, and the Oriental motives in the formation of human relationships. In the works of Plato, the myths about the life of the human soul in the Hereafter are interpreted in different ways. It was pointed out that the issue of eternal spirituality was of great importance in the works of Plato. Our goal is to rely on sources, to analyze social-philosophical, moral views of Plato and his ideas about man. It was revealed that Plato was influenced by ancient Myths, the Upanishads, when creating his own dialogues.
\end{abstract}

\section{INTRODUCTION}

Studying the history of philosophy requires a definition of the role of philosophy in the social consciousness forms and determines that the material life of society is dependent on social practice, its relative independence, and its internal development, its internal logic. The history of philosophical doctrines of the past has been considered as a step taken and its study is of great importance today. Indeed, studying the philosophical views of great thinkers is always a matter of urgency. That is why the scientists in the field of social sciences are increasingly focusing on the study of the philosophical heritage, the spiritual values created by Western-born scholars. To do so, we need to be armed with the current philosophical pursuits. "Many intellectuals, especially young people, are not familiar with their ideas because the works of many great philosophers worldwide have not been published in Uzbek yet. Is not it possible to comprehend the books of Socrates and scholars such as Plato, Nietzsche and Freud, the books of modern foreign philosophers, and comment and comment in Uzbek? ... For example, if we study the theoretical views of Freud, the ideas of pragmatism and existentialism, the philosophy of Berdyaev and others ... In many matters we may not agree with Western philosophers' ideas, especially individualism, divination of egoism views. But we need to take them into account, to recognize what they have, and to deny their worthlessness. "[1] And then we can accurately and objectively evaluate the development of philosophical thoughts, the development of thinking in our country, the main problems of contemporary philosophy. Therefore, studying philosophical issues, philosophical heritage remains one of the most pressing issues in the agenda.

\section{Explanation of thematic literature}

The great philosopher of the antiquity philosophy is the Greek philosopher Plato's philosophical, social and historical literature, including the history of philosophy, in his own way, by a great number of researchers. There are many examples of

Revised Manuscript Received on July 22, 2019.

Ruzmatova Gulnoz Mirakhrarovna, National University of Uzbekistan named after Mirzo Ulugbek Professor of the Department of Philosophy and Logic, Faculty of Social Sciences, Doctor of Philosophical Sciences Email: gulnoz68@mail.ru this, and we can find solutions that can fully meet today's requirements. It is also interesting to note that A.F.Losev [9], S.Ya.Shemenman -Tultstein [2], Dj.Tompson [6], A.L.Bogolyubov, Yu.P.Narsky and others, pamphlets, articles, and articles.

\section{MATERIALS AND METHODS}

In the course of the research were used scientifically-philosophical principles such as systematics, theoretical-deductive conclusions, analysis and synthesis, historical and logic, comparative analysis.

\section{Analysis and results}

It is striking that Plato addressed the Oriental myths in his own dialogues. It is surprising that he addressed older myths rather than logical concepts in Upanishad. However, in the epoch of the aflotunce philosophy, it is natural that the general use of the "Upanishad", which was created in the VI-IV centuries $\mathrm{BC}$, by Platonic, can be used by Aflotus, in particular, of old philosophy and legendary ideas. Because the legendary form of consciousness in the ancient East was dominated by the times of Plato. Therefore, the legitimate tradition of the ancient prehistoric philosophy seems to be legitimate. Oriental mythology has long been influenced by the Hellenic creatures, and was directly exploited in the trade or enlightenment trips of Greeks to Egypt, Iran and India during the era of Plato $[2,8,31]$. The platitude of the differentiation of Egypt in the State and the Law, especially the Hellenes, and the ancient East, is the center of economic and cultural relations between the Hellenic Republic and the Ionian city of Anatolia.

Plato, who is the creator of idealist dialectics, is based on rational knowledge, although myths play a significant role, and also plays a traditional ideological role. In the works of Plato, the myths about the life of the human soul in the Hereafter are interpreted in different ways. The issue of eternal immortality of the soul always pervaded Plato. In the Sogrot Apologies [3] this issue is put as a rational dilemma: "Death is one of the two: whether or not there is no survival after death, when the dead do not experience anything, or if the beliefs are true, change from one place to another. If you do not feel anything, then you will not dream a dream as if it were a dream; Death is a strange phenomenon ... On the other hand, if death moves from one place to another, is it the place where the dead are, or is there anything better? If any of these arbitrators come to the aid of relief and where there is a fair trial of half a dozen gods consisting of their justice - Minos, Radamant, Eak, Thriptolem and others, is that kind of migration worse? " ]. In the second part of the dilemma, the hypothesis of the judgment in the Hereafter, which was carried out by the daughters of Minus and Renaissance, the daughters of Oceans and Fethiyans, was used by Zeus's

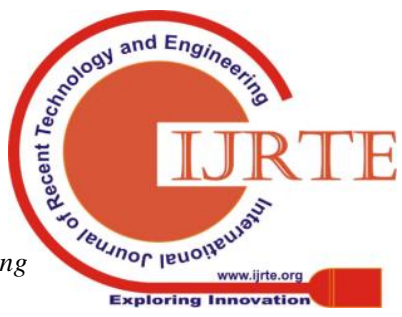




\section{Eastern Melodies in the Text of Plato}

sons in Asia. Asian - Eastern epic of the East. The motif passes through all of Plato's epitaph about the mood of the soul and the reward of the end of the world, including the latest "Consolationes" by the stoicity, which is distinguished by the depth of expression and the content of its contents - false axioms too. From the seven dialogues used in the narrations of the soul's life in the Hereafter (the Sogrot Apologies, Gorgiy, Menon, Fedon, Fedr, State, and Axiox), usually the Minos and Radamant myths. The law of Adrasta ("The Forbidden Epistle of Nemesis") and the Dik deity (Law) in "Fedr" [4, 616a-617e] - The Ananka God ("Zarurat"), and his three daughters, Kloto, Atropos and Laxesis, refer to the judgment of the life of a human being, which combines the past and future of man. In a narration depicted in Fedr, we find a manifestation of the mysterious spirit of Indian "Kath-upanishad", and the reward of the Hereafter, as reported by Plato himself, was reported to Sogrot through the Pamphilian Armenian Era [4, 644, 20]. Era's name differs in different ancient sources [5]. In the interpretation of science as a memory of soul, "Menon" refers to the reward of the Hereafter given to pious souls through Persephone, which, according to researchers, is influenced by Egypt [6].

In general, Plato's idea of the immortality of souls depends on the actions of man in his life, and his appearance in various forms is definitely rooted in the roots. According to Plato, the fact that the human body is "grave" or "imprisonment" is associated with the religious views of the characters (Greek word: exploitation - sema) [4, Phaedr, 82e-83d; Gorgiy, 493a]. When the soul leaves the body after the death of the human soul, it must be purified so that the mercy of the Lord may fall. According to Plato, the spirit of a wise man is purified by his philosophical thinking and the invisible and invisible ideas he has lived in his lifetime. Likewise, Brahman, who deals with promises, is in line with the supreme ideals (in other words, Plato's story) [2, 54]. Hence, we have observed parallelism of Plato and farewell ideas about the immortality of the soul. Now we will see the synthesis of ancient Eastern histories in the dialogues of Plato.

"The Sogrot Apology" [40s - 41s]. In addition to remembering the thoughts of Minos and Radamant, the name of Orpheus is mentioned first among those who want to meet in the reign of the world. [41a] Here, first and foremost, the preference for death to hear death, to communicate with the great poets, wise men and generals, and to enjoy their philosophical conversations, to survive the pain of life, and then to the wise. This motive necessitated the dialogue between the immortality of the soul and the dialogue dedicated to Sacrot's death - "Fedon". However, in the Sogrot Apology, there is the passage of the Oriental narrations, which describes the subject of the migration of the soul, and the eternal immortality of the faltering spirit as a philosophical basis, to the spiritual purity. "Gorgiy" [522e-527e]. The Gospel narrative on punishment and reward in the Hereafter describes Plato's teaching of justice, which is the most important act of good deeds. The Elephant of the Elephant is associated with the name of the feminine poet Evmolp, the goddess of Goddess Demetraus. In the platoon, there are other indications of the influence of the Fatihas, including propagation of duodenal and herbal remedies according to the direction of Sacrot Harmid, the chief physician of the Charmid, 155e-157s, in the Phrykian period in the Phrykian witch, Zalmoksid; The physician argued that the Zalmoxide person simply denied the healing of body parts and said the need for a complete body treatment; The treatment of the head should be accompanied by the treatment of the heart. Plato's rationality is clearly seen here. Zalmoxide's supplication not only cures Garmid's headache but also enhances his mind.

Here, as in the end of the Socratic apologies, the doctrine of the Oriental narratives on the one hand and the justice of the political ideological concepts of Athens, where Plato lived. Sogrot tells his story to the audience that the righteous man does not have the fear of death, and on the contrary, he is inevitably afraid of the death of a person who has many mental illnesses.

However, this is based on the mythological sense of the Indian karma (even though Pythagoras 'doctrine and aristocrats') [4, 32, 33] and the narrative in which it expresses the harmony of Asian and European motives; This sentence is made up of the two sons of Asia (as we have already mentioned, Minos and Radamant) and Eut, a son of Europe; Minos is a neutral referee. Zeus's dominion over the human soul, despite its origin, beauty, richness, or position in society, or in the narrative language, to the spirit "naked" (that is, before the death of a human being, The ruling was typical for moderate democracy in Athens. According to Plato, the spirits of the tyrants, kings, and the rulers of the city will be healed and their evil spirits will be severed. These include tyrants [2, 86-88]. The soul of a normal human or philosopher is pious and just $[2,525]$.

Consequently, Sukrot says, "Perhaps my story seems to be a witchcraft for you, and you listen to her. If our research leads to different, good and true conclusions, there is no surprise in it. But now you see yourself (...) - There is no evidence that we can live in something else that we can trust in. On the contrary, there were many principles, all of which were abolished, and only one was fixed - it would be better to fix it than to endure injustice and may be good in private and social work, and this is the main concern in life. " Thus, the ancient Oriental tradition, enriched with pure Greek materials, can be an ideological basis for the rationalistic (intelligent) principle of Plato.

"Menon" [81b-d]. In the concept of Eleus's mysteries, there are also rational motifs in the aflatox. Demetra's daughter, Persephone, and the wife of the goddess Pluto of the underground reign (Aid) are the rulers of the fate of the spirits who have fallen into the reign of Aid, and divine deities; he will revive the spirit of the souls of those who have spent their lives as godly as possible, and bring them back to life in the ninth year. The immortal (immortal) rebirth is borne out in the new life by embodying all of its previous experiences and thus gaining knowledge. Plato's theory of knowledge and its proportionality in the Oriental narrative are also found in Fedr, Fileb and in Fedon.

"Fedon" in this dialogue dedicated to proving the eternal immortality of the soul, the final narrative describing the power of the earth - Tartar combines the cosmological (universe) images born in the earth (including Anaximandr's Earth skeleton, according to Plato, in a balance between homogeneous homogeneous

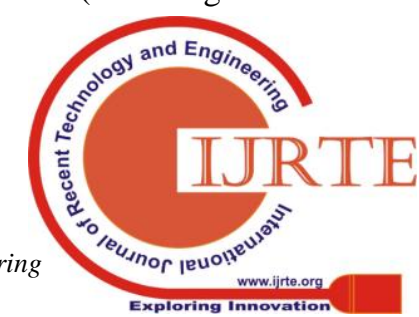


[Phaedr, 108e-109a] [4, 503-504]. There is also a pure aflotunian doctrine about the genome (daymonion) that accompanies a person during his lifetime and watches the soul after the death of the soul. According to this doctrine, there are clear speeches of far-reaching spirits about the end of the chain of different forms of entering into spirits that have been completely purified and that they go to "places that are not as easy to speak as the more beautiful (earthly heavenly country)."

This infinitely clean, hard-to-reach high-end ideal space, confronted by the words of Plato, is a very different, incomplete material and spiritual element, which is similar to the veda Brahmani, because all the material universe is born and reunited when he dies. Older people? The Atman is the spirit of the human soul, who "rescues from the members of his body when he is dying" and returns to his original state, "breathing," and thus the "great space" - breathing in Brahma, which is similar to breathing [8].

In Fedon, the organic transition from this Oriental to the pure Aflotion, ie the soul is completely purified, according to Plato [Phaedrae, 114], the philosophy of life is the basis of wisdom and wisdom, and the reward in the Hereafter [2, 83]. In Fedon, however, Plato's idea of immortality of the soul, in contrast to the fanatic and rational insights of the human soul and death of the body described in the Apocalypse Apologies, is based on the idea of immortality of the spirit: the dialectic of the spirit he has worked out reverses it in the traditional Oriental traditions [7, 483 -487]. In the future - in the dialect of Fedr and State, he is of the same point and only recognizes the return to the dilemma of the next false falsehood in Axiox in the Sukrot apology: the death of the soul with the body, or the loss of feeling - , on the contrary, a joyful life in the dwelling place of pious souls.

"Fedr" [245s-250s]. The narrative of the immortality of the soul here is not only about good qualities, but also connected with poetic inspiration and creativity. In other words, affliction and beauty afflicted the doctrine. The soul itself, according to Plato, is the driving force of everything [Phaedr, 245s-246a]. It is analogous to that of a "double-winged carriage with an insect" [Phaedr, 246b]. Later, on the basis of this verse, the divine spirits spread. According to him, the divine spirit moves around in the sky, watching things around the sky, and other ("traitor") spirits can see heavenly truth, others lose it, and others never get involved. All these are governed by the Law of Adrastias, which depicts the spirits of the spirits and denotes the at least part of divine truth, depriving them of the wings of the soul that is worse than evil and forgetfulness.

Depending on the actions and actions of the spirits during their lifetime, their subsequent rebirth is determined from inanimate subject to wisdom and love. The human spirit can also be passed on to an animal, or vice versa. However, according to Buddhism and Vedas, we can clearly distinguish between all the narratives, especially the winged winged bird, which dominates it. Therefore, [I, 2, 3, 3.4] in the "Katha-upanishad" almost identical figure, the rational conductor-controlling the body of the body of emotion and skin. There are similar images in the aflot. There, both here and there, the thought (consciousness) takes part in the tactics of the tulporine, but the two platoons in the platoon are the dazzling white tulpora, which reflects the delicacy and insight of the soul, and the black tulpora, which is embroidered, . In this smaller difference, the level of interpretation of the Greek philosopher is characterized by rationality from the authors of the Kath. This episode ends with the mystery of Sukrot, revealed in Menon.

"Country" [614a-621d]. Here Plato's doctrine of justice is described by the Sacred Character in the end reward and reward. According to Sogrot, the son of the Armenian, the Pampilian Er was killed in the war, but was buried at the funeral on the twelfth day. Thus, the Earth, which came back to life, tells of its experiences in the Hereafter. Oriental motifs dominate this story. As in the past versions of Plato's narratives about the life of the soul in the Hereafter, it is about the place of divine judgment in Anania and the judges' judgment of dignity. Regardless of the geography of geography and cosmology of the spirits of the spirits, here we find the same palephanic spirit: the spirits are born again, regardless of their kindness; they will judge themselves for themselves: "Be the Lord God!" declares Ananka.

The revival of the early mood and the almost impossible impossibility of getting rid of the "chain of the chain" and the rejection of the Buddhist doctrine led to the impact of the civilian responsibility on the subject by the Greco-Roman ideology of Plato. According to Plato, the tyrant's soul is subjected to severe punishment [2, 81-83] [Gorgiy, 525d, Phaedr, 248e]. This narrative, which is written in the final part of "State," strengthens Platon's teaching of good and justice. In this regard, the final part of the dialogue [Resp., 621b-d] specifically states: "Thus, Glavkop survived by the resurrection of the Earth. He also saves us; If we believe in him, then we can easily go through Leta (the Greek forgetfulness in the Greek mythology) and defile our souls. But we are sure that all of us, if you believe in me, will always walk in the way of the Creator, and that we will always be wise and upright because we are still on the brink of friendship with ourselves and our gods. necessary. If we consider ourselves worthy of the prize as the winner of the competition, then we will be better off here. " At the same time, the particularity of Plato's secular life, which differs from ordinary goodbye and Buddhism pessimism, is of particular interest.

"Axiox" [369e-372a]. Finally, this dialog will end your session as soon as it's released. It was narrated that Aksyox, the fate of the soul after the body's death, had been sent to protect Xerxes Delos, the son of Darius, who was the great-grandson of Gobri's grandson, the Persian proud Gobri's grandson. It seems that he read the myths copied on the copper plate of Apollo and Artemis, (the hyperborey country is actually in the skiff plains or on the ocean coast) $[9,10]$. The origin of this narration goes to the East. The cosmological and eschatological ideas of the story narrated by Gobri correspond to the narratives expressed by Plato in Gorgiy, Fedon and State.

The dome of the dome is domed and the first half of the dome is the god of the gods, and the other part is the place of the goddess of the earthly throne. In the rivers of Kokit and

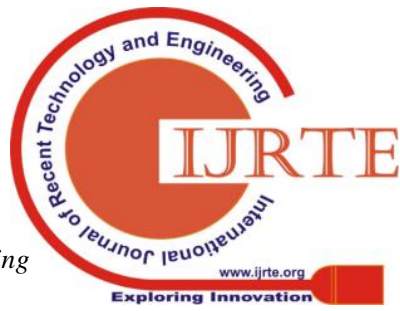


Akheront, which flows from the river, the sins of souls are washed away, and Minos and Radamans are judged in the "valley of truth". Whoever lives with good qualities in life, places them in a wonderful place in the pious spirits. The author of the dialogue portrays happy life in this bright, bright dye. For the spirit of Aksiok, who is famous for his generosity, the place has been set up. The souls of those who have "gone through evil" fall into Ereb and Chaos, "The tantalum is troublesome, and he pulls his stones into the hill, and the carrots carry water constantly and fill the pots with holes ..." [Ahijah, 371a]. We find that these narratives are related to the Eleventh Mysteries: the goddess of eleven (in other words, Persepolis) directs the journey of the spirits in the Hereafter. The author of these narrations, Plato, points to the fact that the body is a dungeon of the soul, and that the soul is given to a peaceful philosophical interpretation when it is removed from the darkness [Axiox, 370b].

\section{CONCLUSION}

Thus, in the "Socratic apologies", the objective-idealistic tendency that is supposed to be the basis of austereism's purely rationality and traditional mythology fights together. The second one will win. Ancient Oriental ideas about the migration of the spirit to this victory undoubtedly have an impact. Plato's views on ontology, cosmology, and mythology are closer to Eastern philosophical doctrines. But we can see the impact of Greek social life on gnoseology, ethics, and aesthetic doctrines.

Within the scope of the research, it can be used to extrapolate the socio-philosophical thinking, to write monographs, tutorials, to form an independent opinion, to form a positive attitude to the history of philosophy, to the theory of knowledge. Nowadays it studies and analyzes various doctrines, it is reflected in the right decision making on the basis of modern requirements and the use of our young people in expanding their scientific-spiritual outlook, using them as a comprehensible human

\section{REFERENCES}

[1] Karimov I.A. I believe in the strong will of our wise people // Fidokor. June 8, 2000.

[2] Sheynman-Topshine S.Ya. Plato i vediyskaya philosophy. - M.: Nauka, 1978. Dialogue "Alkiviad I".

[3] Arology Socrat. 40c.- 41a.

[4] Plato. Sochienia. - T. 1-3. - M .: Mysl, 1968-1972.

[5] This name is considered a Jewish name, which is described by Luke in the Bible by Joseph as a carpenter, while Clauston Alexander was compared to Pamfilian Erani Zardus; but in any case, the Asian man is talking about.

[6] Thomson Dj. Issledovaniya po istorii drevnegrecheskogo obshchestva. Doistoricheskiy Aegean mir. - M., 1958;

[7] I'm sorry. Aeschylos und Athen. - Berlin, 1957.

[8] Chattopadx'yaya D Lokayata darshana. - M .: Mysl, 1961.

[9] Losev A.F. (commentary on "Menon" // v. Knap: Plato, Sochienia, T. 1. - M .: Mysl, 1968.

[10] "Brixadaran-uplighter", IV, 3, 3;

[11] "Floating", II, 12, 18, 22;

[12] "Completion-rising", II, 1,

[13] "Mundaka-upanish", II, 2;

[14] "Shvetashvatara- rising", III.
[15] Strunila M. Do you have hyperbole? // Technique. 1984. - No. 10. 